\title{
Die Geburt eines Buches
}

\section{Iris Ritzmann}

Prof. Dr. med. et lic. phil., Mitglied der Redaktion Medizingeschichte
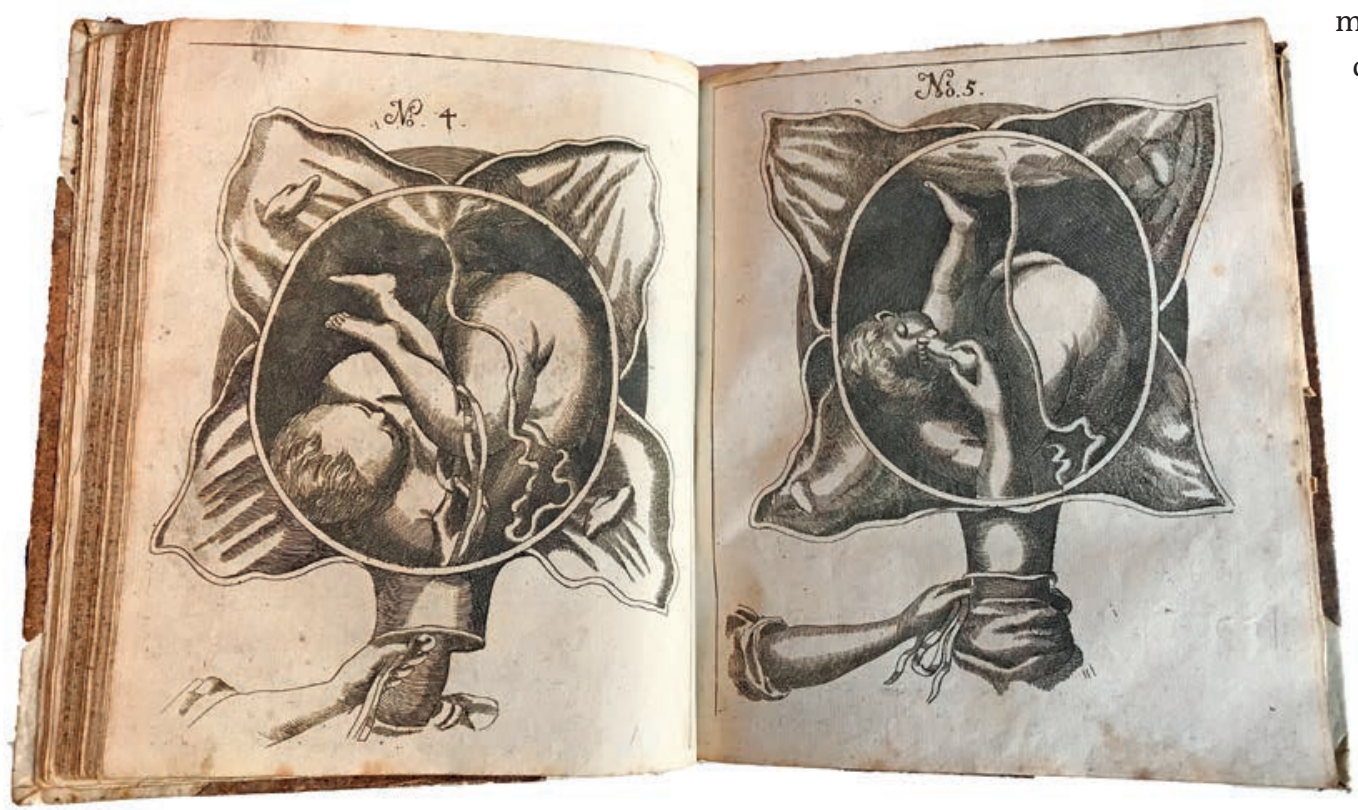

Drehung des Kindes, Tafeln 4 und 5, in «Die Königl. Preussische und Chur-Brandenb. Hof-Wehe-Mutter, Das ist: Ein höchst nöthiger Unterricht von schweren und unrecht-stehenden Geburthen ... mit denen dißfalls erregten Controvers-Schrifften vermehret» von Justine Dittrich Siegemund, Berlin 1741, Sammlung Dr. Franz Käppeli.

mit abdrucken. Dennoch erregte das Buch heftige Kritik männlicher Geburtshelfer. Siegemundin reagierte darauf, indem sie diese Zuschriften in späteren Ausgaben mit veröffentlichte.

Die Besonderheit ihres Hebammenbuchs gründet nicht allein auf diesem Umgang mit Kritik. Siegemundin bereicherte die Geburtshilfe mit einem neuen Instrument zur Entfernung von Myomen, obschon metallene Instrumente damals nur von männlichen Geburtshelfern benutzt werden sollten. Als eine der ersten Fachpersonen achtete sie auf die Lage des Hinterhaupts des ungeborenen Kindes, um den Geburtsverlauf einzuschätzen. Schliesslich entwickelte sie eine neue Technik, den "gedoppelten Handgriff». Er bestand darin,

Der letzte Beitrag der Rubrik «Seiten-Blicke» schlägt für einmal ein Buch auf, das von einer Frau verfasst wurde. Justine Siegemund, geborene Dittrich, publizierte ihr Lehrbuch für Hebammen erstmals 1690, zwei Jahre nachdem sie zur Brandenburg-Preussischen Hofhebamme am Hof des Soldatenkönigs Friedrich Wilhelm ernannt worden war.

$\mathrm{Zu}$ ihrem Beruf kam die Pfarrerstochter nicht über den üblichen Ausbildungsgang, sondern als Betroffene einer Fehleinschätzung durch mehrere Hebammen. Schockiert vom Unwissen dieser Frauen, erwarb sie eigenständig fundierte Hebammenkenntnisse, wodurch sie über die Jahre zur meistgefragten Hebamme der ganzen Region aufstieg.

Die «Siegemundin", wie sie genannt wurde, war sich bewusst, welches Wagnis sie als Autorin eines Lehrbuchs auf sich nahm. Daher legte sie ihr Manuskript drei Predigern und der medizinischen Fakultät von Frankfurt a.O. vor und liess die positiven Gutachten mit einem Stöckchen und Bandschlingen das ungeborene Kind bei der gefürchteten Querlage auf die Füsse zu drehen, wodurch eine Geburt eher möglich wurde. Das Geheimnis des durchschlagenden Erfolgs dieses Werks liegt aber auch in den schönen und feinen Kupferstichen, die anatomische Strukturen und verschiedene Geburtslagen abbilden und für deren Herstellung vermutlich Siegemundins eigene Zeichnungen als Vorlage dienten.

Mit ihrem Buch schuf sie ein anerkanntes Lehrbuch für Hebammen und Ärzte. Aber es hatte auch eine zweite Funktion: «Solcher gestalt ist dieses Buch, das lange, wie in einer Geburt gestecket, ans Licht gekommen, und soll, weil ich keine Kinder zur Welt gebohren, das seyn, was ich der Welt hinterlasse.»

\section{Bildnachweis}

๑ Museum für medizinhistorische Bücher Muri (mmbm.ch) 